\title{
Linear Quadratic Optimal Control of a Spar-Type Floating Offshore Wind Turbine in the Presence of Turbulent Wind and Different Sea States
}

\section{Roberto Luiz Ramos}

Federal University of ABC (UFABC), Center of Engineering, Modeling and Applied Social Sciences, Av. dos Estados, 5001, Bairro Santa Terezinha, Santo André, SP 09210-580, Brazil; roberto.ramos@ufabc.edu.br; Tel.: +55-11-4996-8252

Received: 29 November 2018; Accepted: 5 December 2018; Published: 7 December 2018

\begin{abstract}
This paper presents the design of a linear quadratic (LQ) optimal controller for a spar-type floating offshore wind turbine (FOWT). The FOWT is exposed to different sea states and constant wind turbulence intensity above rated wind speed. A new LQ control objective is specified for the floater-turbine coupled control, in accordance with standard requirements, to reduce both rotor speed fluctuations and floater pitch motion in each relevant sea state compared with a baseline proportional-integral (PI) controller. The LQ weighting matrices are selected using time series of the wind/wave disturbances generated for the relevant sea states. A linearized state-space model is developed, including the floater surge/pitch motions, rotor speed, collective blade pitch actuation, and unmeasured environmental disturbances. The wind disturbance modeling is based on the Kaimal spectrum and aerodynamic thrust/torque coefficients. The wave disturbance modeling is based on the Pierson-Moskowitz spectrum and linearized Morison equation. A high-fidelity FOWT simulator is used to verify the control-oriented model. The simulation results for the OC3-Hywind FOWT subjected to turbulent wind show that a single LQ controller can yield both rotor speed fluctuation reduction of $32-72 \%$ and floater pitch motion reduction of $22-44 \%$ in moderate to very rough sea states compared with the baseline PI controller.
\end{abstract}

Keywords: floating offshore wind turbine; spar; floater-turbine coupled control; control-oriented modeling; linear quadratic (LQ) optimal control; turbulent wind; sea states; disturbance modeling

\section{Introduction}

A floating offshore wind turbine (FOWT) is a marine system designed to generate power from wind over deep waters. The FOWT is a cost-effective solution for wind energy generation in water depths over $60 \mathrm{~m}$ compared with its fixed-platform counterpart. FOWT technology benefits include higher wind speeds, rational use of the ocean space, and mitigation of the visual effects usually associated with shallow-water and land-based wind turbines [1]. The electricity production from FOWTs is suitable for several countries, in particular Brazil where significant offshore wind resources are available over deep waters, associated with high capacity factors, several densely populated cities are close to the sea, and the long coastline is usually exposed to calm/moderate wave conditions [2].

An FOWT is constituted of the wind turbine (rotor-nacelle assembly including the drivetrain and control system) [3], the floater (platform/tower), and the station keeping system. The stabilization concept considered herein is based on a spar floater and catenary mooring lines. The spar floater has good performance with respect to wave load response, due to the relatively small cross-sectional area at the sea surface and its deep draft. The hydrostatic stability of a spar-type FOWT is based on the ballast system and is mainly due to the distance between the center of buoyancy and the center of 
gravity. To avoid large motions and associated loads, the resonance frequencies are chosen out of the wave bandwidth, which leads to a structural design with low rigid-body natural frequencies of surge and pitch [4].

Control design is crucial to achieve the desired FOWT performance under varying environmental conditions. The control system affects the rotor speed fluctuations and nacelle inclination, as well as the floater stability and global motions, which are associated with the power production, serviceability, structural damage, and fatigue life of an FOWT. Experimental results about the active blade pitch and generator control effects on the FOWT response are presented in [5]. FOWT control design involves aspects of both wind turbine control [6] and marine craft motion control [7,8].

Due to the spar-type FOWT lightly-damped pitch motion and associated low natural frequency, and to the strong floater-turbine coupling, the application of onshore wind turbine control strategies in the above rated wind speed region, especially rotor speed proportional-integral (PI) control, can yield large rigid-body floater pitch oscillations and associated loads. The phenomenon is called control-induced instability or negative damping, and it occurs only above rated wind speed. It is related to the non-minimum phase zeros of the transfer function from the collective blade pitch control input to the rotor speed output, which can limit the closed-loop bandwidth and deteriorate the rotor speed regulation [9].

To mitigate the negative damping, Fischer [10] proposed the use of the generator torque as an additional control input using narrow-band feedback control to reduce the associated drivetrain loads. Pedersen [11] proposed an energy shaping feedforward approach to the FOWT stabilization problem. Larsen and Hanson [12] and Jonkman [13] proposed PI controllers with reduced gains (detuned PI control). Despite the inherent simplicity for tuning and practical purposes, single-input-single-output (SISO) controllers cannot accommodate the strongly coupled floater-turbine dynamics. Passive control using tuned mass dampers (TMDs) has been proposed to limit the nacelle/floater motions [14], however, TMD applications involve concerns about cost and performance in different mean wind speed regions.

To avoid the negative damping, the standard DNVGL-ST-0119 [15] addresses the requirements for the floater-turbine coupled control. For a spar floater, the excitation in the pitch mode of motion must be limited as much as possible to minimize fatigue damage. The performance of the floater-turbine combined control system shall be demonstrated according to the system motion requirements for the selected environmental conditions. The wind and wave energy contents in the relevant sea states and their distribution over frequencies shall be considered in the FOWT structural and control system design, involving suitable power spectral density models for wind and waves.

Model-based multivariable methods can be applied to the floater-turbine coupled control problem. Assuming limited rotor speed fluctuations and small floater motions about an operating (equilibrium) point, an FOWT can be modeled by linearized equations of motion. In this case, linear control design methods based on state-space models can be applied to synthesize controllers according to specified objectives.

The research on linear model-based multivariable control for FOWTs can be carried out according to two main aspects:

- Mathematical modeling, involving the coupled floater-turbine motions and environmental (wind and wave) disturbances;

- Controller design in the presence of relevant environmental conditions.

Wind turbine analysis software, such as FAST [16], BLADED [17], and HAWC2 [18], has been developed for the modeling of FOWTs. In particular, the high-fidelity simulator FAST, developed by the National Renewable Energy Laboratory (NREL), is free software that can generate a linearized state-space model about an operating point, associated with a chosen mean wind speed, including only selected degrees of freedom (DOFs) for control design. The wind input disturbance matrix, which relates the wind inputs to the wind-induced forces and moments, is generated based on the Blade 
Element Momentum (BEM) theory [6]. However, the wave input disturbance matrix, which relates the sea state inputs (significant wave heights and wave peak frequencies) to the wave-induced forces and moments, cannot be obtained directly from the FAST linearization feature since only wind input disturbances are available [16].

In marine craft motion control literature [7,8], wave disturbance modeling can be accomplished using the so-called force Response Amplitude Operators (RAOs or transfer functions). Force RAOs relate the wave amplitudes and frequencies (sea states) to the wave-induced forces and moments, and can be generated using potential flow solvers. For slender-cylinder platforms, such as the spar floater considered herein [4], the wave disturbance modeling in the time domain, as well as the added mass and hydrodynamic damping, can be based on the Morison Equation (small body hydrodynamics) [19-21]. In this case, fluid memory effects (convolution integrals in the equations of motion) and radiation damping can be neglected [22]. The stochastic/equivalent linearization of the quadratic viscous damping (drag) in the Morison equation, which is necessary for the application of linear control methods, is addressed in [23] for an offshore wind turbine.

Control-oriented modeling of FOWTs including the wave disturbance is presented by Homer and Nagamune [24], Betti et al. [25,26], and Sandner et al. [27]. Homer and Nagamune developed and verified, via FAST, a physics-based 3-D rigid-body model for a semisubmersible floater using the Pierson-Moskowitz (P-M) wave spectral model $[7,8]$ and Morison equation. Betti et al. developed and verified, via FAST, 2-D models for tension leg [25] and spar platforms [26], applying the P-M spectrum and Morison equation. Sandner et al. developed and verified, via FAST, a 3-D model for a spar floater using the Morison equation with preview information of water free-surface elevation. Reduced-order 2-D coupled modeling in still water is carried out by Fontanella et al. [28].

As for the controller design, several schemes based on linear quadratic (LQ) optimal control [29] have been proposed in the FOWT control literature [30-34]. LQ control is a well-established model-based technique that can stabilize, regulate and optimize multivariable systems based on a quadratic cost function, involving the state variables and control inputs. The LQ controller tuning is carried out via chosen constant weighting matrices. Control input weighting can be used to impose actuator saturation constraints. LQ control yields a fixed-gain linear state feedback control law that guarantees stability and robustness. However, LQ optimal control design for FOWTs is not straightforward since the standard regulator problem does not consider the influence of persistent disturbances, such as wind and waves.

To tackle the disturbance modeling, Lindeberg [30] designed optimal controllers using a wave disturbance model based on a fixed wave peak frequency. Ramos investigated LQ optimal control design subject to mean wind speed variations in a regular sea state [31]. Lemmer et al. [32] proposed LQ controller design based on frequency-domain performance evaluation. Christiansen et al. [33] proposed a state-space model with observer design including wind turbulence disturbance estimated by an Extended Kalman Filter (EKF). Namik and Stol [34] designed a state feedback controller and a disturbance accommodating controller, using individual blade pitch control (IPC) to reject step changes in the hub-height wind speed disturbance acting on a spar-type FOWT.

However, the above references did not consider the objective of reducing the coupled floater-turbine motions in different sea states. Simulation results were presented for a single sea state or averaged over several environmental conditions. Therefore, the advantage of the proposed advanced controllers over the PI controller in each relevant sea state was not demonstrated.

In this regard, the Hywind data sets of realistic environmental conditions provided by Equinor (formerly Statoil) for an operating FOWT revealed the occurrence of different sea states above rated wind speed [35], according to the sea state descriptions shown in $[7,8]$. Therefore, the reduction of coupled floater-turbine motions in each sea state of interest must be considered in advanced control design to avoid poor FOWT performance in a particular environmental condition.

In this paper, a new LQ control objective is specified for the floater-turbine coupled control, in accordance with standard requirements [15], to reduce both rotor speed fluctuations and floater 
pitch motion in each relevant sea state compared with a baseline PI controller. The wind turbulence intensity is assumed to be constant. The LQ weighting matrices are selected using time series of the wind/wave disturbances generated for the relevant sea states.

The performance of the FOWT control system depends on the floater type. In particular, the simulation results presented by Namik and Stol [34] revealed the low effectiveness of IPC for the pitch motion reduction of a spar-type FOWT. The small improvement of IPC with respect to a baseline PI controller is mainly due to the lower pitch natural frequency of spar-type FOWTs compared to wind energy systems based on barge and tension leg platforms, in conjunction with the actuator saturation constraints. Therefore, collective blade pitch actuation is adopted herein for control design.

In this paper, a linearized, controllable, state-space model of the coupled spar floater-turbine dynamics is developed. The modeling approach is based on FAST linearization [16] including the wave disturbance modeled as first-order wave loads due to long-crested (unidirectional) irregular seas acting on the spar floater, using the P-M spectrum and linearized Morison equation. The wind disturbance is modeled as wind turbulence loads acting on the rotor, using the Kaimal spectrum and aerodynamic thrust/torque coefficients computed by FAST linearization [16] based on BEM theory [6]. The OC3-Hywind system aerodynamic and hydrodynamic properties [3,4] are adopted. The modeling is based on moored floating rigid-body dynamics [36]. The FOWT model formulation is similar to Fossen's compact matrix-vector notation for the marine craft equations of motion $[7,8]$.

Assuming aligned wind/waves and collective blade pitch actuation, as justified above, the sway and roll motions are neglected. The delta-connection design of the mooring lines yields large yaw stiffness, which limits the pitch-yaw coupling and associated gyroscopic effects, while the deep draft of the spar floater limits the heave motion. The three dominant DOFs, involving the floater surge/pitch motions and rotor speed, are assumed to be measured for state feedback. The LQ controller is designed to avoid the excitation of high-frequency structural responses. A constant generator torque strategy is adopted above rated wind speed. The wind turbulence and sea states are assumed to be unmeasured. Wind shear and wake effects due to multiple FOWTs in a floating wind farm are neglected. Swell, ocean currents, and second-order wave loads are not considered.

The 3-DOF control-oriented model, including the wind and wave disturbances, is verified using the high-fidelity wind turbine simulator FAST [16]. The simulations carried out by Namik and Stol [34] using the full FAST 21-DOF model revealed that the second tower and blade bending modes are not relevant for a spar-type FOWT, thus only the first tower and drivetrain flexibility effects are taken into account. Therefore, the verification of the control-oriented model is based on comparison with a 10-DOF aero-hydro-servo-elastic nonlinear FAST model, including 6-DOF spar floater motions, drivetrain rotational flexibility, tower fore-aft and side-to-side bending modes, rotor speed, Kaimal wind turbulence model, P-M long-crested irregular waves, and a gain scheduled PI controller. A baseline detuned PI controller is designed for model verification and performance evaluation of the LQ control system.

The verification results confirm the good quality of the proposed 3-DOF model for spar-type FOWT control design based on collective blade pitch actuation. Considering that the dynamics of the linearized model is almost invariant at different mean wind speeds above rated wind speed, according to the single value analysis carried out in $[25,26]$, the FOWT model linearized at the middle point of the above rated wind speed region is adopted herein to represent the system behavior for control design.

The LQ control method is applied to the benchmark OC3-Hywind FOWT, which is constituted of the NREL 5-MW horizontal axis wind turbine [3] mounted on a spar floater with catenary mooring lines [4]. It is assumed that the FOWT is subjected to turbulent wind modeled according to the International Electrotechnical Commission (IEC) standard 61400-1 with constant reference turbulence intensity Class B [37]. Three relevant sea states are selected for control design based on the Pierson-Moskowitz (P-M) wave spectral model [7,8], probability of occurrence, and load effects. 
The simulation results show that a single LQ controller can yield significant reduction of both rotor speed fluctuations and floater pitch motion in moderate to very rough sea states compared with the baseline PI controller.

\section{The FOWT Control Problem and Control Objectives}

For FOWT control design above rated wind speed, the oscillatory coupled floater-turbine motions due to turbulent wind and different sea states are modeled using a linearized state-space representation, involving the floater surge/pitch motions and rotor speed about an operating point, in conjunction with the collective blade pitch control input and environmental disturbances.

The control objectives and constraints (performance/control law specifications) are as follows:

- Stabilize the FOWT system;

- Reduce both rotor speed fluctuations and floater pitch motion in each relevant sea state compared with a baseline PI controller. Constant wind turbulence intensity is assumed;

- Limit collective blade pitch actuation, considering saturation constraints;

- Attenuate unmeasured disturbances with known spectral characteristics (feedforward control is not considered);

- Apply LQ optimal control, assuming that the floater surge/pitch motions and rotor speed are measured for state feedback (observer design is not considered).

The proposed FOWT control problem can be stated as follows: considering a linearized state-space model of the spar-type FOWT to be controlled, in conjunction with the above control objectives and constraints, a single LQ controller must be found, if one exists.

\section{Modeling of Environmental Conditions}

\subsection{Wind Turbulence}

The spectral density function for the longitudinal component of the wind turbulence is based on the Kaimal spectrum [6]:

$$
S_{\text {wind }}(f)=4 \sigma_{u}^{2} \frac{\frac{L_{1 u}}{V}}{\left(1+6 f \frac{L_{1 u}}{V}\right)^{\frac{5}{3}}},
$$

where $f$ is the frequency, $\bar{V}$ is the mean wind speed, $\sigma_{u}=I_{u} \bar{V}$ is the standard deviation of the longitudinal turbulence component, and $L_{1 u}$ is a characteristic length scale. According to the Normal Turbulence Model (NTM) [37], the longitudinal turbulence intensity $I_{u}$ is given by:

$$
I_{u}=I_{r e f}\left(0.75+\frac{5.6}{\bar{V}}\right)
$$

The reference intensity $I_{r e f}$ depends on the wind class. For the considered IEC Class B wind turbulence condition, $I_{r e f}$ is 0.14 [37]. The wind turbulence can be expressed by generating time series (realizations) from the wind spectrum $S_{\text {wind }}(f)$, as follows [19]:

$$
\delta V=\sum_{m=1}^{M} \sqrt{2 S_{\text {wind }}\left(f_{m}\right) \Delta f} \cos \left(2 \pi f_{m} t+\phi_{m}\right),
$$

where $M$ must be sufficiently large, $\Delta f$ is the frequency interval, and $\phi_{m}$ are independent random variables uniformly distributed between 0 and $2 \pi$. 


\subsection{Sea States}

A sea state is represented by a significant wave height $H_{s}$ and wave peak period $T_{p}$. A modified version of the P-M wave spectrum, adopted herein, is expressed by $[7,8]$ :

$$
S_{\text {wave }}(\omega)=\mathrm{A} \omega^{-5} e^{-\mathrm{B} \omega^{-4}}=\frac{1}{2 \pi} \frac{5}{16} H_{s}^{2} T_{p}\left(\frac{\omega}{2 \pi} T_{p}\right)^{-5} e^{-\frac{5}{4}\left(\frac{\omega}{2 \pi} T_{p}\right)^{-4}} .
$$

For the simulations of sea state conditions carried out in this paper, $H_{s}$ and $T_{p}$ are related by:

$$
\mathrm{A}=\alpha g^{2}=\frac{4 \pi^{3} H_{s}^{2}}{\left(0.710 T_{p}\right)^{4}} \Rightarrow T_{p} \approx 5 \sqrt{H_{s}}, \quad B=\frac{16 \pi^{3}}{\left(0.710 T_{p}\right)^{4}}
$$

where $\alpha=8.1 \times 10^{-3}$ is the Phillips constant. The horizontal acceleration of water particles at depth $z$ $(z \leq 0)$ for first-order linear irregular waves in deep waters can be expressed by generating time series (realizations) from the wave spectrum $S_{\text {wave }}(\omega)$, as follows [20,21]:

$$
\dot{u}_{w} \approx \sum_{n=1}^{N}-\sqrt{2 S_{\text {wave }}\left(\omega_{n}\right) \Delta \omega} \omega_{n}^{2} e^{k_{n} z} \cos \left(\omega_{n} t+\phi_{n}\right),
$$

where $N$ must be sufficiently large, $k_{n}$ is the wave number, $\omega_{n}$ is the circular frequency, $\Delta \omega$ is a constant difference between successive frequencies, and $\phi_{n}$ are independent random variables uniformly distributed between 0 and $2 \pi$. For deep water waves, the wave number $k_{n}$ and the circular frequency $\omega_{n}$ are related by the dispersion relation $\omega_{n}^{2} \approx g k_{n}[21]$.

Table 1 shows the relevant sea states for FOWT model verification and control design.

Table 1. Sea states for floating offshore wind turbine (FOWT) model verification and control design.

\begin{tabular}{ccc}
\hline Sea States & Significant Wave Height $\boldsymbol{H}_{\boldsymbol{s}}(\mathrm{m})$ & Wave Peak Period $\boldsymbol{T}_{\boldsymbol{p}}(\mathbf{s})$ \\
\hline Moderate & 2 & 7.07 \\
Rough & 4 & 10 \\
Very rough & 6 & 12.25 \\
\hline
\end{tabular}

\section{FOWT Modeling for Control: Coupled Floater-Turbine Motions and Wind/Wave Disturbances}

The scheme of the proposed control-oriented model for a spar-type FOWT is illustrated in Figure 1. The main assumptions are described in Section 1.

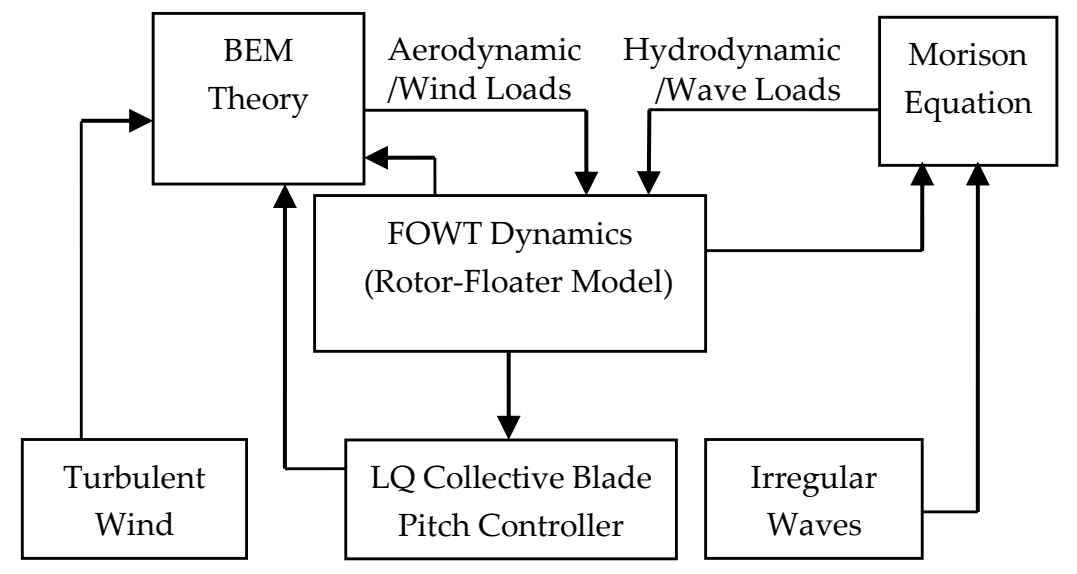

Figure 1. Block diagram of the proposed spar-type FOWT model for control design and simulation. 


\subsection{Kinematics}

The six global modes of motion or rigid-body DOFs for the floater-turbine coupled control are defined with respect to an inertial reference frame with orthogonal axes $(x, y, z)$ associated with the orientation of the wind turbine [15]. The six DOFs are referred to as surge (translation along the longitudinal axis $x$ in the main wind direction), sway (translation along the lateral axis $y$, transversal to the main wind direction), heave (translation along the vertical axis $z$ ), roll (rotation about the longitudinal axis $x$ ), pitch (rotation about the lateral axis $y$ ), and yaw (rotation about the vertical axis $z$ ). The reference frame is determined by the equilibrium state in the absence of environmental disturbances, that is, the FOWT is floating at rest in still water without wind effects. This reference frame or coordinate system $(x, y, z)$ fixed to the undisturbed state and rotated to the wind direction is considered to be inertial, in a similar way to the seakeeping frame for marine craft dynamics $[7,8]$.

The plane $(x, y)$ coincides with the mean water free surface $(z=0)$. The axis $z$ is positive vertically upwards along the line that passes through the center of gravity of the undisturbed FOWT (centerline). The plane $(x, y)$ and the axis $z$ determine the origin of the adopted reference frame. The axis $x$ is positive downwind. The axis $y$ is positive to the left when looking downwind. The rotational motions are positive right turning about the respective axes. The rigid-body motions of the moored FOWT in wind and waves are assumed to be small in the plane $(x, z)$ with dominant 2-DOF surge and pitch modes. As mentioned in Section 1, the wind and waves are assumed to be aligned. Figure 2 illustrates the considered spar-type FOWT and the coordinate system.

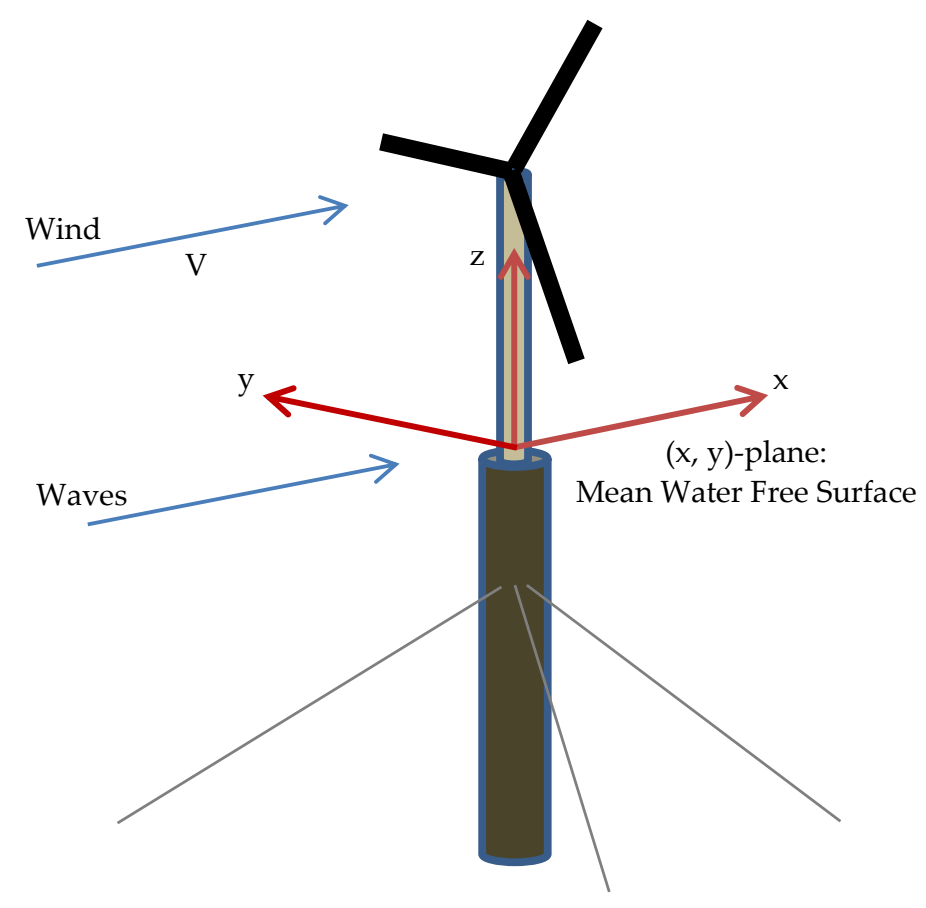

Figure 2. Sketch of the spar-type FOWT and coordinate system.

\subsection{Floater Modeling}

The floater modeling for control involves rigid-body dynamics, hydrostatics, mooring restoring, and hydrodynamics.

\subsubsection{Floater Rigid-Body Dynamics}

The rigid-body spar floater dynamics in the inertial reference frame can be expressed by a 2-DOF linear equation of motion in the time domain based on the Newton's second law, as follows: 


$$
\mathbf{M}_{R B} \ddot{\xi}=\mathbf{f}_{h s}+\mathbf{f}_{\text {moor }}+\mathbf{f}_{\text {hydro }}+\mathbf{f}_{\text {aero }},
$$

where $\xi=\left[\xi_{1}, \xi_{5}\right]^{T}$ is the vector of floater motion coordinates (surge and pitch, respectively) in the inertial reference frame (fixed at the FOWT undisturbed or initial equilibrium state), $\mathbf{M}_{R B}$ is the rigid body mass matrix, $\mathbf{f}_{h s}$ is the vector of hydrostatic (buoyancy/gravitational) restoring surge force and pitch moment, $\mathbf{f}_{\text {moor }}$ is the vector of mooring restoring surge force and pitch moment, $\mathbf{f}_{h y d r o}$ is the vector of hydrodynamic surge force and pitch moment computed by using the Morison Equation (added mass, linearized viscous damping, and wave excitation loads), and $\mathbf{f}_{\text {aero }}$ is the vector of aerodynamic surge force and pitch moment due to the wind turbine loads on the floater, including the rotor aerodynamic damping, collective blade pitch actuation, and wind excitation. As described in Section 1, the hydrodynamic load vector $\mathbf{f}_{\text {hydro }}$ for a spar floater does not include convolution integrals associated with fluid memory effects [22].

The rigid body mass matrix is given by:

$$
\mathbf{M}_{R B}=\left[\begin{array}{cc}
m & m z_{g} \\
m z_{g} & I_{y y}
\end{array}\right],
$$

where $m$ is the FOWT (spar floater and wind turbine) total mass, $z_{g}$ is the position of the center of gravity of the undisturbed FOWT along the axis $z$ (negative value), and $I_{y y}$ is the FOWT moment of inertia (about the origin) associated with the pitch motion.

\subsubsection{Hydrostatics and Mooring Restoring}

The hydrostatic (buoyancy/gravitational) restoring surge force and pitch moment can be approximated by the linear model $\mathbf{f}_{h s}=-\mathrm{C} \xi$. The matrix of hydrostatic coefficients is given by:

$$
\mathbf{C}=\left[\begin{array}{cc}
0 & 0 \\
0 & C_{55}
\end{array}\right],
$$

where the buoyancy /gravitational restoring pitch moment coefficient $C_{55}$ is computed as [4]:

$$
C_{55}=\rho_{w} \nabla g z_{b}-m g z_{g}+\rho_{w} g I_{\text {area }}
$$

where $\rho_{w}$ is the sea water density, $\nabla$ is the submerged volume or displaced volume of the fluid, $g$ is the acceleration due to gravity, $z_{b}$ is the position of the center of buoyancy of the undisturbed FOWT along the axis $z$ (negative value), and $I_{\text {area }}$ is the FOWT area moment of inertia. The total mass of the FOWT structure $m$ equals the displaced water mass $\rho_{w} \nabla$, that is, $m=\rho_{w} \nabla$. Considering that the area moment of inertia is negligible for a spar floater, the FOWT hydrostatic stability is determined by the distance between the center of buoyancy and the center of gravity.

The mooring restoring surge force and pitch moment can be approximated by the linear model $\mathbf{f}_{\text {moor }}=-\mathbf{C}_{m} \xi$, where the matrix elements depend on the stiffness coefficient in surge and on the position of the fairleads.

\subsubsection{Hydrodynamics}

Assuming unidirectional wind-generated waves in the surge direction and small floater motions, the total surge force and pitch moment can be obtained from the Morison equation for deep waters, by integrating along the floater draft the inline force and the associated moment, respectively, due to each strip. The surge force on a floater strip of diameter $D$ and length $d z$ at depth $z(z \leq 0)$ is given by [19-21]: 


$$
\begin{gathered}
d F_{h y d r o}=\rho_{w} \frac{\pi D^{2}}{4} \dot{u}_{w} d z+\rho_{w} C_{A} \frac{\pi D^{2}}{4}\left(\dot{u}_{w}-\dot{u}_{b}\right) d z+ \\
\frac{1}{2} \rho_{w} C_{D} D\left|u_{w}-u_{b}\right|\left(u_{w}-u_{b}\right) d z
\end{gathered}
$$

where $u_{w}$ is the horizontal velocity of water particles at depth $z, u_{b}$ is the horizontal body velocity at depth $z, C_{A}$ is the added mass coefficient, and $C_{D}$ is the viscous drag coefficient. The first term of the surge force in Morison Equation (11) is the Froude-Krylov force, associated with pressure effects due to the undisturbed incident waves, the second term is associated with added mass effects, and the third term is associated with viscous drag effects.

The horizontal floater velocity at depth $z(z \leq 0)$ associated with small surge/pitch motions can be approximated by $u_{b} \approx \dot{\xi}_{1}+z \dot{\xi}_{5}$. The pitch moment due to a floater strip of length $d z$ at depth $z$ $(z \leq 0)$ is given by:

$$
d M_{\text {hydro }}=z d F_{\text {hydro }} .
$$

In order to obtain a suitable model for LQ controller design, the quadratic viscous drag force (per unit length) in irregular waves can be approximated using stochastic linearization. However, as pointed out by Housseine et al. [23], the advantage of stochastic linearization with respect to regular wave linearization may be small in the presence of uncertainties related to the Morison equation coefficients. In this case, the hydrodynamic viscous force (per unit length) can be approximated using equivalent linearization of the quadratic drag due to floating body motions in regular waves combined with an absolute velocity approach [21].

Assuming surge and pitch motions in a particular sea state modeled by $\xi_{i}=\Xi_{i} \cos \left(\omega t+\varepsilon_{i}\right)$, $i=1,5$, respectively, the relevant quadratic drag force terms (per unit length) related to the floater motions in Morison Equation (11) can be linearized according to [23]:

$$
\left|\dot{\xi}_{i}\right| \dot{\xi}_{i} \approx \frac{8}{3 \pi} \omega \Xi_{i} \dot{\xi}_{i}
$$

In this paper, the approximation given by Equation (13) is carried out according to the hydrodynamic viscous damping coefficients obtained using FAST linearization (damping matrix without aerodynamic effects) [16]. Integrating the surge force and pitch moment due to a cylinder element given by Equations (11) and (12), respectively, along the spar floater draft, and considering the linearized viscous drag due to the approximation given by Equation (13), the hydrodynamic loads can be written as follows:

$$
\mathbf{f}_{\text {hydro }}=\left[\begin{array}{c}
F_{\text {hydro }} \\
M_{\text {hydro }}
\end{array}\right]=-\mathbf{A} \ddot{\xi}-\mathbf{B}_{v} \dot{\xi}+\mathbf{f}_{\text {wave, }}
$$

where $\mathbf{A}$ is the matrix of hydrodynamic added mass coefficients, $\mathbf{B}_{v}$ is the matrix of hydrodynamic linearized viscous damping coefficients (assumed to be frequency-independent), and $\mathbf{f}_{\text {wave }}$ is the vector of first-order wave excitation loads on the spar floater. From the results obtained above, and including additional linear damping in surge $B_{11 l}$ [4], Equation (7) for the floater surge/pitch motions in the time domain can be rewritten as follows:

$$
\begin{aligned}
& {\left[\begin{array}{cc}
m+A_{11} & m z_{g}+A_{15} \\
m z_{g}+A_{51} & I_{y y}+A_{55}
\end{array}\right]\left[\begin{array}{c}
\ddot{\xi}_{1} \\
\ddot{\xi}_{5}
\end{array}\right]+\left[\begin{array}{cc}
B_{11 v}+B_{11 l} & B_{15 v} \\
B_{51 v} & B_{55 v}
\end{array}\right]\left[\begin{array}{c}
\dot{\xi}_{1} \\
\dot{\xi}_{5}
\end{array}\right]+} \\
& {\left[\begin{array}{cc}
C_{11 m} & C_{15 m} \\
C_{51 m} & C_{55 m}+C_{55}
\end{array}\right]\left[\begin{array}{c}
\xi_{1} \\
\xi_{5}
\end{array}\right]=\left[\begin{array}{l}
f_{\text {aero }}^{\{1\}} \\
f_{\text {aero }}^{\{5\}}
\end{array}\right]+\left[\begin{array}{c}
f_{\text {wave }}^{\{1\}} \\
f_{\text {wave }}^{\{5\}}
\end{array}\right]}
\end{aligned}
$$

\subsection{Wind Turbine Rotor Modeling}

The wind turbine rotor modeling involves rotor aerodynamics, rigid-body dynamics, and collective blade pitch actuation. 


\subsubsection{Rotor Aerodynamics}

The aerodynamic loads on the rotor can be modeled using the BEM theory, which is basically a strip method, by integrating the blade element axial thrust force and torque along the blade length. The computed rotor thrust force and torque can be formulated, respectively, as follows [6]:

$$
\begin{gathered}
F_{\text {aero }}(\mathbf{x})=\frac{\rho_{a} \pi R^{2}}{2} C_{T}(\lambda, \beta) V_{e}^{2}, \\
Q_{a e r o}(\mathbf{x})=\frac{\rho_{a} \pi R^{3}}{2} C_{Q}(\lambda, \beta) V_{e}^{2}, \\
V_{e} \approx V-\dot{\xi}_{1}-h \dot{\xi}_{5}, \quad V=\bar{V}+\delta V, \quad \Omega=\bar{\Omega}+\delta \Omega, \quad \beta=\bar{\beta}+\delta \beta,
\end{gathered}
$$

where $\mathbf{x}=\left[\dot{\xi}_{1}, \dot{\xi}_{5}, \Omega, \beta, V\right]^{T}, \rho_{a}$ is the air density, $R$ is the rotor radius, $C_{T}$ is the non-dimensional thrust coefficient, $C_{Q}$ is the non-dimensional torque coefficient, $V_{e}$ is the wind speed relative to the rotor, $h$ is the position of the rotor hub of the undisturbed FOWT along the $z$ axis (positive value), $V$ is the wind speed, $\Omega$ is the rotor rotational speed, $\beta$ is the collective blade pitch angle, $\bar{V}$ is the 10-min mean wind speed, $\bar{\Omega}$ is the nominal rotational speed, and $\bar{\beta}$ is the collective blade pitch angle at the equilibrium state. The terms $\delta V, \delta \Omega$, and $\delta \beta$ account for the wind turbulence, rotor speed fluctuations, and collective blade pitch angle variations about the equilibrium state, respectively. The thrust and torque coefficients depend on the tip speed ratio $\lambda=\Omega R / V_{e}$ and on the collective blade pitch angle $\beta$.

Linearizing the aerodynamic rotor thrust force and torque using $1^{1^{\text {st }} \text {-order truncated Taylor-series }}$ expansion about $\overline{\mathbf{x}}=[0,0, \bar{\Omega}, \bar{\beta}, \bar{V}]^{T}$, gives, respectively:

$$
\begin{gathered}
F_{\text {aero }}(\mathbf{x}) \approx F_{\text {aero }}(\overline{\mathbf{x}})+\left.\sum_{i=1}^{5} \frac{\partial F_{\text {aero }}}{\partial x_{i}}\right|_{\bar{x}} \delta x_{i}, \\
Q_{\text {aero }}(\mathbf{x}) \approx Q_{\text {aero }}(\overline{\mathbf{x}})+\left.\sum_{i=1}^{5} \frac{\partial Q_{\text {aero }}}{\partial x_{i}}\right|_{\bar{x}} \delta x_{i},
\end{gathered}
$$

where $\delta \mathbf{x}=\mathbf{x}-\overline{\mathbf{x}}=\left[\dot{\xi}_{1}, \dot{\xi}_{5}, \delta \Omega, \delta \beta, \delta V\right]^{T}$.

The surge force and pitch overturning moment on the floater in the inertial reference frame due to the wind turbine rotor aerodynamics are given by:

$$
\mathbf{f}_{\text {aero }}=\left[\begin{array}{c}
f_{\text {aero }}^{\{1\}} \\
f_{\text {aero }}^{\{5\}}
\end{array}\right]=\left[\begin{array}{c}
F_{\text {aero }}(\mathbf{x}) \\
h F_{\text {aero }}(\mathbf{x})
\end{array}\right] .
$$

\subsubsection{Rotor Rigid-Body Dynamics}

The rotor dynamics in the above rated wind speed region can be expressed by [3]:

$$
I_{d} \dot{\Omega}=I_{d} \delta \dot{\Omega}=Q_{a e r o}(\mathbf{x})-N_{\text {gear }} Q_{g},
$$

where $I_{d}$ is the inertia of the drivetrain system, $N_{\text {gear }}$ is the gearbox ratio, and $Q_{g}$ is the generator torque (assumed to be constant). The drivetrain inertia is given by:

$$
I_{d}=I_{r}+N_{g e a r}^{2} I_{g}
$$

where $I_{r}$ is the rotor inertia and $I_{g}$ is the generator inertia.

The wind turbine rotor blade azimuth angle fluctuation $\delta \psi_{r}$ is related to the rotor speed fluctuation $\delta \Omega$ as follows:

$$
\delta \dot{\psi}_{r}=\delta \Omega .
$$


Therefore, the wind turbine rotor equation of motion becomes:

$$
I_{d} \delta \ddot{\psi}_{r}=Q_{a e r o}(\mathbf{x})-N_{\text {gear }} Q_{g} .
$$

Considering a constant torque strategy in the above rated wind speed region, the equilibrium collective blade pitch angle $\bar{\beta}$, for the chosen mean wind speed $\bar{V}$ and nominal rotational speed $\bar{\Omega}$, is obtained from:

$$
Q_{a e r o}(\overline{\mathbf{x}})-N_{\text {gear }} Q_{g}=0 .
$$

\subsubsection{Collective Blade Pitch Actuation}

The perturbation aerodynamic control input vector $\delta \boldsymbol{\tau}_{\text {control }}$ due to the collective blade pitch actuation on the FOWT rotor can be written using aerodynamic thrust and torque derivatives with respect to the collective blade pitch angle (negative values), as follows:

$$
\delta \boldsymbol{\tau}_{\text {control }}(\overline{\mathbf{x}})=\left[\left.\left.\left.\frac{\partial F_{\text {aero }}}{\partial \beta}\right|_{\overline{\mathbf{x}}^{\prime}} \quad h \frac{\partial F_{\text {aero }}}{\partial \beta}\right|_{\overline{\mathbf{x}}^{\prime}} \frac{\partial Q_{\text {aero }}}{\partial \beta}\right|_{\overline{\mathbf{x}}}\right]^{T} \delta \beta=\mathbf{b}(\overline{\mathbf{x}}) \delta \beta .
$$

\subsection{Environmental Disturbances}

The modeling of environmental disturbances for FOWT control involves the wind disturbances $\delta \boldsymbol{\tau}_{\text {wind }}$ acting on the rotor and the wave disturbances $\boldsymbol{\tau}_{\text {wave }}$ acting on the floater.

\subsubsection{Wind Disturbances}

The disturbance vector due to the wind turbulence $\delta \boldsymbol{\tau}_{\text {wind }}$ acting on the rotor can be written using aerodynamic thrust and torque derivatives with respect to the wind speed (positive values), as follows:

$$
\delta \boldsymbol{\tau}_{\text {wind }}(\overline{\mathbf{x}})=\left[\left.\left.\left.\frac{\partial F_{\text {eero }}}{\partial V}\right|_{\overline{\mathbf{x}}^{\prime}} \quad h \frac{\partial F_{\text {eero }}}{\partial V}\right|_{\overline{\mathbf{x}}^{\prime}} \quad \frac{\partial \mathrm{Q}_{\text {aero }}}{\partial V}\right|_{\overline{\mathbf{x}}}\right]^{T} \delta V .
$$

The vector of wind excitation loads $\delta \boldsymbol{\tau}_{\text {wind }}$ includes the aerodynamic thrust force, overturning moment, and rotor torque as a function of the wind turbulence speed $\delta V$ given by Equation (3).

\subsubsection{Wave Disturbances}

The disturbance vector due to the wave excitation $\boldsymbol{\tau}_{\text {wave }}$ acting on the floater is given by:

$$
\boldsymbol{\tau}_{\text {wave }}=\left[\begin{array}{lll}
f_{\text {wave }}^{\{1\}}, f_{\text {wave }}^{\{5\}} & 0
\end{array}\right]^{T} .
$$

The vector of first-order wave excitation loads $\boldsymbol{\tau}_{\text {wave }}$ includes the surge force $f_{\text {wave }}^{\{1\}}$ and the pitch moment $f_{\text {wave }}^{\{5\}}$ on the floater. The inertia effects dominate the wave excitation loads in Morison Equation (11) due to the relatively small Keulegan-Carpenter (KC) numbers for the considered spar floater and relevant sea states [4]. Therefore, the surge force due to the wave excitation on each strip of the spar floater draft with diameter $D$ and length $d z$ at depth $z(z \leq 0)$ can be approximated by:

$$
d f_{\text {wave }}^{\{1\}} \approx \rho_{w} C_{M} \frac{\pi D^{2}}{4} \dot{u}_{w} d z
$$

where $C_{M}=1+C_{A}$ is the inertia coefficient and $\dot{u}_{w}$ is the horizontal acceleration of water particles at depth $z(z \leq 0)$ given by Equation (6). The pitch moment due to the wave excitation on each strip of the spar floater draft with diameter $D$ and length $d z$ at depth $z(z \leq 0)$ is given by:

$$
d f_{\text {wave }}^{\{5\}}=z d f_{\text {wave }}^{\{1\}}
$$


The total surge force and pitch moment in Equation (29) can be obtained by integrating along the floater draft the wave excitation loads on a floater strip given by Equations (30) and (31), respectively.

\subsection{Coupled Floater-Turbine Model: FOWT Equations of Motion}

The coupled floater-turbine 3-DOF model can be obtained from the floater surge/pitch dynamics and wind turbine rotor dynamics modeled above, including the collective blade pitch actuator forces/moments and the wind/wave disturbances. The FOWT model formulation is similar to Fossen's compact matrix-vector notation for marine craft motion control $[7,8]$. The FOWT equations of motion are formulated as follows:

$$
\mathbf{M} \ddot{\mathbf{q}}+\mathbf{D}(\overline{\mathbf{x}}) \dot{\mathbf{q}}+\mathbf{G q}=\left[\begin{array}{lll}
F_{\text {aero }}(\overline{\mathbf{x}}), & h F_{\text {aero }}(\overline{\mathbf{x}}), & 0
\end{array}\right]^{T}+\delta \boldsymbol{\tau}_{\text {control }}(\overline{\mathbf{x}})+\delta \boldsymbol{\tau}_{\text {wind }}(\overline{\mathbf{x}})+\boldsymbol{\tau}_{\text {wave }}
$$

where $\mathbf{q}=\left[\xi_{1}, \xi_{5}, \delta \psi_{r}\right]^{T}$ is the vector of FOWT system variables, including the floater surge/pitch motions in the inertial reference frame and the wind turbine rotor blade azimuth angle fluctuations. The matrices M, D and G, associated with the FOWT inertia, aerodynamic/hydrodynamic damping, and stiffness (gravitational, buoyancy, and mooring effects), respectively, are given by:

$$
\begin{gathered}
\mathbf{M}=\left[\begin{array}{ccc}
m+A_{11} & m z_{g}+A_{15} & 0 \\
m z_{g}+A_{51} & I_{y y}+A_{55} & 0 \\
0 & 0 & I_{d}
\end{array}\right], \\
\mathbf{D}(\overline{\mathbf{x}})=\left[\begin{array}{ccc}
B_{v 11}+B_{l 11}+\left.\frac{\partial F_{\text {aero }}}{\partial V}\right|_{\overline{\mathbf{x}}} & B_{v 15}+\left.h \frac{\partial F_{\text {aero }}}{\partial V}\right|_{\overline{\mathbf{x}}} & -\left.\frac{\partial F_{\text {aero }}}{\partial \Omega}\right|_{\overline{\mathbf{x}}} \\
B_{v 51}+\left.h \frac{\partial F_{\text {earo }}}{\partial V}\right|_{\overline{\mathbf{x}}} & B_{v 55}+\left.h^{2} \frac{\partial F_{\text {aero }}}{\partial V}\right|_{\overline{\mathbf{x}}} & -\left.h \frac{\partial F_{\text {aero }}}{\partial \Omega}\right|_{\overline{\mathbf{x}}} \\
\left.\frac{\partial Q_{\text {aero }}}{\partial V}\right|_{\overline{\mathbf{x}}} & \left.h \frac{\partial Q_{\text {aero }}}{\partial V}\right|_{\overline{\mathbf{x}}} & -\left.\frac{\partial Q_{\text {aero }}}{\partial \Omega}\right|_{\overline{\mathbf{x}}}
\end{array}\right], \\
\mathbf{G}=\left[\begin{array}{ccc}
C_{m 11} & C_{m 15} & 0 \\
C_{m 51} & C_{m 55}+C_{55} & 0 \\
0 & 0 & 0
\end{array}\right] .
\end{gathered}
$$

The matrix $\mathbf{D}$ includes the floater-turbine coupling terms due to the aerodynamic and hydrodynamic effects. It is written using aerodynamic thrust and torque derivatives with respect to the wind speed (positive values) and to the rotor rotational speed. The matrices $\mathbf{M}, \mathbf{D}$ and $\mathbf{G}$ include the floater surge/pitch coupling terms due to the inertia/added mass, aerodynamic and hydrodynamic damping, and stiffness restoring effects, respectively.

The mean wind speed $\bar{V}$ affects the equilibrium position of the FOWT. The new equilibrium position can be determined as follows:

$$
\left(\mathbf{C}+\mathbf{C}_{m}\right)\left[\begin{array}{c}
\bar{\xi}_{1} \\
\bar{\xi}_{5}
\end{array}\right]=\left[\begin{array}{c}
F_{\text {aero }}(\overline{\mathbf{x}}) \\
h F_{\text {aero }}(\overline{\mathbf{x}})
\end{array}\right],
$$

where $\xi_{1}=\bar{\xi}_{1}+\delta \xi_{1}$ and $\xi_{5}=\bar{\xi}_{5}+\delta \xi_{5}$.

Therefore, omitting the dependence on $\bar{x}$, the FOWT control-oriented model can be formulated using a compact matrix-vector notation with perturbation variables about the new equilibrium state $\overline{\mathbf{q}}=\left[\bar{\xi}_{1}, \bar{\xi}_{5}, 0\right]^{T}$, as follows:

$$
\mathbf{M} \delta \ddot{\mathbf{q}}+\mathbf{D} \delta \dot{\mathbf{q}}+\mathbf{G} \delta \mathbf{q}=\delta \boldsymbol{\tau}_{\text {control }}+\delta \boldsymbol{\tau}_{\text {wind }}+\boldsymbol{\tau}_{\text {wavee }}
$$

where $\delta \mathbf{q}=\mathbf{q}-\overline{\mathbf{q}}=\left[\delta \xi_{1}, \delta \xi_{5}, \delta \psi_{r}\right]^{T}$. 
The FOWT control-oriented model reveals the floater-turbine and surge-pitch cross-coupling coefficients associated with the multivariable behavior and coupled dynamics, which justify the proposed LQ optimal control design approach.

\subsection{Linearized State-Space Model}

From the coupled floater-turbine model given by Equation (37), a state-space model is obtained for LQ controller design, as follows:

$$
\dot{\mathbf{x}}_{p}=\mathbf{A}_{p} \mathbf{x}_{p}+\mathbf{B}_{p} \mathbf{u}+\mathbf{E}_{p} \mathbf{w}, \quad \mathbf{x}_{p}=\left[\delta \mathbf{q}^{T}, \delta \dot{\mathbf{q}}^{T}\right]^{T},
$$

where $\mathbf{x}_{p}$ is the state vector of perturbation variables about the new equilibrium state of the FOWT plant, associated with the floater surge/pitch motions and rotor blade azimuth angle fluctuations represented by the vector $\delta \mathbf{q}=\left[\delta \xi_{1}, \delta \xi_{5}, \delta \psi_{r}\right]^{T}, \mathbf{u}=\delta \beta$ is the scalar collective blade pitch control input, and $\mathbf{w}=\delta \boldsymbol{\tau}_{\text {wind }}+\boldsymbol{\tau}_{\text {wave }}$ is the environmental disturbance vector due to the wind turbulence and sea states. The state-space matrices are given by:

$$
\mathbf{A}_{p}=\left[\begin{array}{cc}
0_{3 \times 3} & \mathbf{I}_{3 \times 3} \\
-\mathbf{M}^{-1} \mathbf{G} & -\mathbf{M}^{-1} \mathbf{D}
\end{array}\right], \quad \mathbf{B}_{p}=\left[\begin{array}{c}
0_{3 \times 3} \\
\mathbf{M}^{-1}
\end{array}\right] \mathbf{b}, \quad \mathbf{E}_{p}=\left[\begin{array}{c}
0_{3 \times 3} \\
\mathbf{M}^{-1}
\end{array}\right] .
$$

\section{Controller Design for a Spar-Type FOWT}

\subsection{LQ Controller Design}

Figure 3 shows the scheme of the proposed LQ control for a spar-type FOWT.

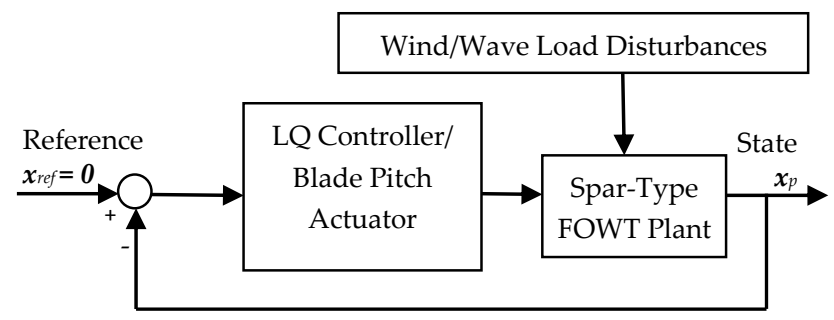

Figure 3. Block diagram of the proposed linear quadratic (LQ) control with state feedback for a spar-type FOWT.

For the design of the single LQ controller, an optimization problem must be solved, as described in Section 2, aiming at reducing floater-turbine motions compared with a baseline PI controller, using constrained collective blade pitch actuation in the presence of turbulent wind and different sea states described in Section 3. Assuming full state feedback, the single LQ controller is designed and simulated based on the developed linearized state-space model and on time series of the wind and wave disturbances.

For a linear optimal control problem [29], the feedback gain matrix $\mathbf{K}$ is obtained from the Riccati matrix differential equation for specified $\mathbf{Q}$ and $\mathbf{R}$ state and control input weighting matrices, respectively, associated with a quadratic cost function involving the FOWT state and the collective blade pitch control input, given by:

$$
J=\int_{0}^{\infty}\left(\mathbf{x}_{p}^{\mathrm{T}} \mathbf{Q} \mathbf{x}_{p}+\mathbf{u}^{\mathrm{T}} \mathbf{R} \mathbf{u}\right) d t
$$

The control objective of reducing both rotor speed fluctuations and floater pitch motion subject to collective blade pitch actuator saturation is considered by means of the $\mathbf{Q}$ and $\mathbf{R}$ state and control input weighting matrices, respectively. It is assumed that the actuator is constrained in magnitude 
(0deg $<\beta<90 \mathrm{deg})$ and rate $(-8 \mathrm{deg} / \mathrm{s}<\dot{\beta}<8 \mathrm{deg} / \mathrm{s})$. The full-state feedback control law is given by:

$$
\mathbf{u}=\delta \beta=-\mathbf{K} \mathbf{x}_{p}=-\mathbf{K}_{1} \delta \mathbf{q}-\mathbf{K}_{2} \delta \dot{\mathbf{q}},
$$

where the fixed-gain matrix $\mathbf{K}$ is given by:

$$
\mathbf{K}=\mathbf{R}^{-1} \mathbf{B}_{p}^{\mathrm{T}} \mathbf{P}
$$

where the matrix $\mathbf{P}$ is the solution of the algebraic matrix Riccati equation:

$$
\mathbf{P A}_{p}+\mathbf{A}_{p}^{\mathrm{T}} \mathbf{P}-\mathbf{P B}_{p} \mathbf{R}^{-1} \mathbf{B}_{p}^{\mathrm{T}} \mathbf{P}+\mathbf{Q}=0 .
$$

Equations (38) and (41) determine the closed-loop dynamics, involving linear damping and stiffness characteristics associated with the state-space matrix $\mathbf{A}_{p}-\mathbf{B}_{p} \mathbf{K}$. To design an LQ controller according to a specified quadratic cost function, the FOWT system must be controllable, that is, to achieve a stable closed-loop system, the controllability matrix

$$
\mathbf{M}_{p}=\left[\mathbf{B}_{p}\left|\mathbf{A}_{p} \mathbf{B}_{p}\right| \ldots \mid\left(\mathbf{A}_{p}\right)^{5} \mathbf{B}_{p}\right]
$$

must be of full row rank.

Considering the FOWT state vector $\mathbf{x}_{p}=\left[\delta \xi_{1}, \delta \xi_{5}, \delta \psi_{r}, \delta \dot{\xi}_{1}, \delta \dot{\xi}_{5}, \delta \Omega\right]^{T}$ and the control input $\mathbf{u}=\delta \beta$, constant diagonal weighting matrices are initially estimated according to desired maximum values of the state variables $x_{p, i}^{\max }, i=1 \ldots 6$, and of the control input $u^{\max }$ based on the FOWT equilibrium values $\left(\bar{\xi}_{1}, \bar{\xi}_{5}, \bar{\Omega}, \bar{\beta}\right)$ and surge/pitch natural frequencies $\left(\omega_{n 1}, \omega_{n 5}\right)$. The elements of the LQ weighting matrices are given by:

$$
\mathbf{Q}_{i i}=\left(x_{p, i}^{\max }\right)^{-2}, \quad \mathbf{R}=\left(u^{\max }\right)^{-2} .
$$

The LQ weighting matrices are adjusted using time series of the wind and wave disturbances simulated for the considered turbulent wind and different sea state conditions, in order to reduce the coupled floater-turbine motions compared with a baseline PI controller.

\subsection{Baseline PI Controller Design}

For the baseline PI rotor speed controller design, the collective blade pitch angle input is given by the feedback control law [12,13]:

$$
\mathbf{u}=\delta \beta=K_{I} \int_{0}^{t} \delta \Omega(\tau) d \tau+K_{P} \delta \Omega(t)=K_{I} \delta \psi_{r}(t)+K_{P} \delta \dot{\psi}_{r}(t),
$$

where the control parameters are determined according to the measured or estimated mean wind speed, considering desired damping ratio $\zeta_{c}$ and natural frequency $\omega_{n c}$, as follows [12,13]:

$$
K_{I}=\frac{I_{d} \omega_{n c}^{2}}{-\left.\frac{\partial Q_{\text {aero }}}{\partial \beta}\right|_{\overline{\mathbf{x}}}}, \quad K_{P}=\frac{2 \zeta_{c} K_{I}}{\omega_{n c}} .
$$

To avoid instability (negative damping) and to obtain adequate stability margins, a PI rotor speed controller with associated natural frequency slightly lower than the FOWT pitch natural frequency (detuned gains) is chosen $\left(\omega_{n c}=0.2 \mathrm{rad} / \mathrm{s}\right)[12,13]$. A damping ratio of 0.7 is adopted.

The performance of the LQ controller, assuming constant wind turbulence intensity, is evaluated in comparison with that of the baseline PI controller based on the reduction of both rotor speed fluctuations and floater pitch motion in each relevant sea state, as follows: 


$$
\begin{gathered}
\text { Rotor speed fluctuation reduction }=\frac{\sigma_{P I, \Omega}-\sigma_{L Q, \Omega}}{\sigma_{P I, \Omega}} \times 100(\%) \\
\text { Floater pitch motion reduction }=\frac{\sigma_{P I, \tilde{\xi}_{5}}-\sigma_{L Q, \xi_{5}}}{\sigma_{P I, \xi_{5}}} \times 100(\%)
\end{gathered}
$$

where $\sigma_{P I, \Omega}$ is the standard deviation of the rotor speed due to the baseline PI controller, $\sigma_{L Q, \Omega}$ is the standard deviation of the rotor speed due to the LQ controller, $\sigma_{P I, \xi_{5}}$ is the standard deviation of the floater pitch angle due to the baseline PI controller, and $\sigma_{L Q, \xi_{5}}$ is the standard deviation of the floater pitch angle due to the LQ controller.

\section{Simulation Results: OC3-Hywind FOWT}

\subsection{Verification of the Control-Oriented Model: Comparison with FAST/NREL}

The linearized state-space model is verified by comparison with simulation results obtained from the high-fidelity nonlinear aero-hydro-servo-elastic code FAST /NREL [16] for the benchmark OC3-Hywind spar-type FOWT [3,4] subject to the environmental conditions described in Section 3. As mentioned in Section 1, the simulations carried out in [34] using the full FAST 21-DOF model revealed that the second tower and blade bending modes are not relevant for a spar-type FOWT, thus those modes are not considered for the verification of the state-space model, and only the first tower and drivetrain flexibility effects are taken into account.

Therefore, the model verification is based on comparison with a 10-DOF nonlinear high-fidelity FAST model, including 6-DOF spar floater motions, drivetrain rotational flexibility, tower fore-aft and side-to-side bending modes, rotor rotational speed, IEC Class B Kaimal wind turbulence, and P-M long-crested irregular waves. The 3-DOF control-oriented model includes the baseline detuned PI controller, while the 10-DOF high-fidelity model includes the FAST gain scheduled PI (GSPI) controller [16]. Table 2 shows the simulation results (average of the results from six realizations with different seed numbers), involving the standard deviations of both rotor speed and floater pitch angle for the FAST model and for the control-oriented model.

Table 2. Verification of the FOWT model for control design.

\begin{tabular}{ccccc}
\hline Sea States & $\begin{array}{c}\text { FAST Model } \\
\text { STD of Rotor Speed (rpm) }\end{array}$ & $\begin{array}{c}\text { Control Model } \\
\text { STD of Rotor Speed (rpm) }\end{array}$ & $\begin{array}{c}\text { FAST Model } \\
\text { STD of Floater Pitch (deg) }\end{array}$ & $\begin{array}{c}\text { Control Model } \\
\text { STD of Floater Pitch (deg) }\end{array}$ \\
\hline Moderate & 0.9256 & 0.8582 & 0.7964 & 0.7326 \\
Rough & 0.9448 & 0.8777 & 0.8231 & 0.8004 \\
Very rough & 0.9969 & 0.9360 & 0.9086 & 0.9943 \\
\hline
\end{tabular}

Table 2 reveals that the standard deviation values of both rotor speed and floater pitch obtained from the control-oriented model are close to the results given by the high-fidelity nonlinear simulator FAST. Therefore, the nonlinearity due to the FOWT behavior away from the operating (equilibrium) point is not significant under the considered environmental conditions. The tower and drivetrain flexibility effects are not relevant as well, that is, the rigid body assumption is justified. Moreover, the floater sway, heave, roll, and yaw DOFs do not influence significantly the system response. The verification results confirm the good quality of the proposed 3-DOF model for FOWT control design based on collective blade pitch actuation.

\subsection{Performance of LQ Control in Turbulent Wind and Different Sea States}

To demonstrate the ability of the designed single LQ controller to meet the control objectives specified in Section 2, involving stabilization and reduction of both rotor speed fluctuations and floater pitch motion in relevant sea states, the responses of the OC3-Hywind FOWT [3,4] due to LQ control and PI control are compared. The environmental conditions specified in Section 3 are considered for the simulations, involving the three sea states shown in Table 1 and constant wind turbulence intensity above rated wind speed. 
The closed-loop performance evaluation is carried out via simulations in the time domain for the entire floating system, in accordance with standard requirements [15]. For each environmental condition (combined wind and waves), six 600-s simulations are carried out using different random seeds based on realizations (time series) of the stochastic wind and wave loads.

For the control-oriented model parameters of the OC3-Hywind FOWT, the controllability matrix is of full row rank, that is, the FOWT system is controllable. Therefore, an LQ controller with full state feedback can be designed to provide stabilization. The stability of the designed closed-loop FOWT system is verified by eigenvalue analysis (the eigenvalues have negative real parts).

The LQ weighting matrices for all sea states, adjusted via simulations, are given by:

$$
\begin{aligned}
& \mathbf{Q}=\operatorname{diag}\left\{\left(0.27 \bar{\xi}_{1}\right)^{-2},\left(0.76 \bar{\xi}_{5}\right)^{-2},(0.18 \bar{\Omega})^{-2},\left(0.27 \omega_{n 1} \bar{\xi}_{1}\right)^{-2},\left(0.76 \omega_{n 5} \bar{\xi}_{5}\right)^{-2},(0.22 \bar{\Omega})^{-2}\right\}, \\
& \mathbf{R}=(0.43 \bar{\beta})^{-2}
\end{aligned}
$$

or, approximately:

$$
\begin{aligned}
& \mathbf{Q}=\operatorname{diag}\left\{(3 \mathrm{~m})^{-2},(2 \mathrm{deg})^{-2},(0.22 \mathrm{rad})^{-2},(0.15 \mathrm{~m} / \mathrm{s})^{-2},(0.43 \mathrm{deg} / \mathrm{s})^{-2},(2.7 \mathrm{rpm})^{-2}\right\} \\
& \mathbf{R}=(6.4 \mathrm{deg})^{-2}
\end{aligned}
$$

Figures 4-6 show the simulation results, involving time series of the floater pitch angle, rotor speed, and collective blade pitch angle, for the baseline PI controller and the designed single LQ controller in moderate, rough and very rough sea states, respectively.
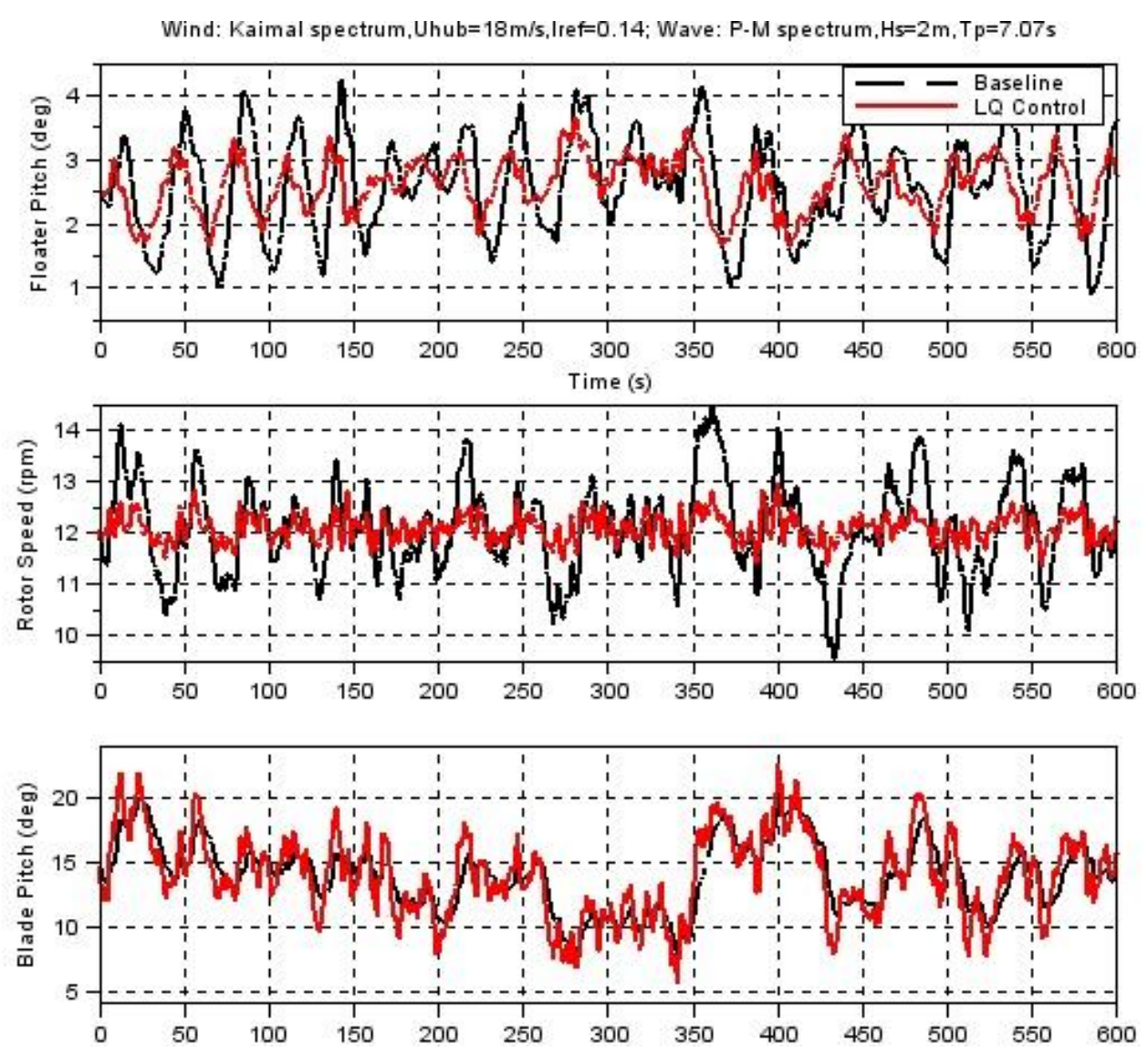

Figure 4. LQ control of a spar FOWT—moderate sea state. 

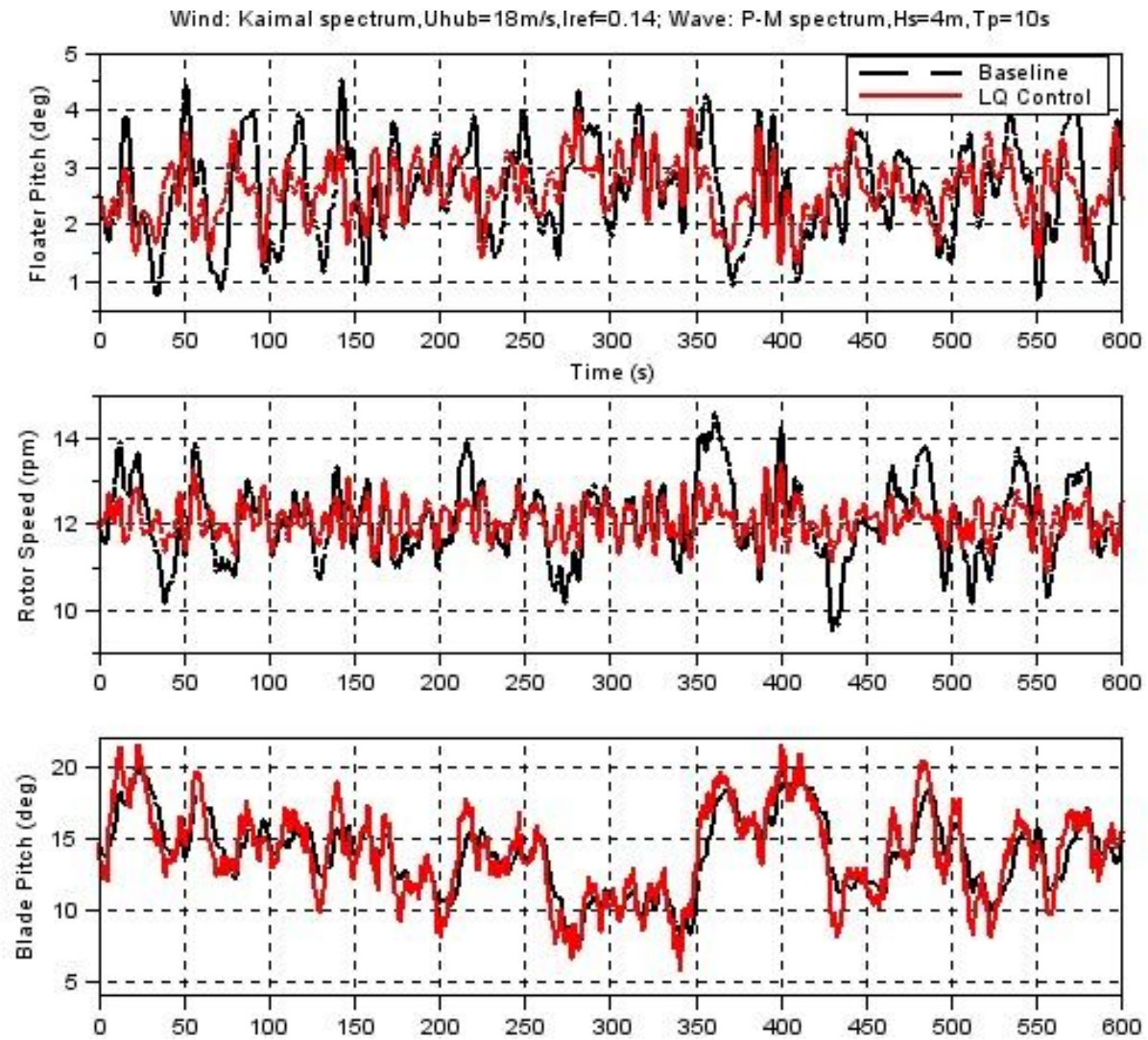

Figure 5. LQ control of a spar FOWT—rough sea state.
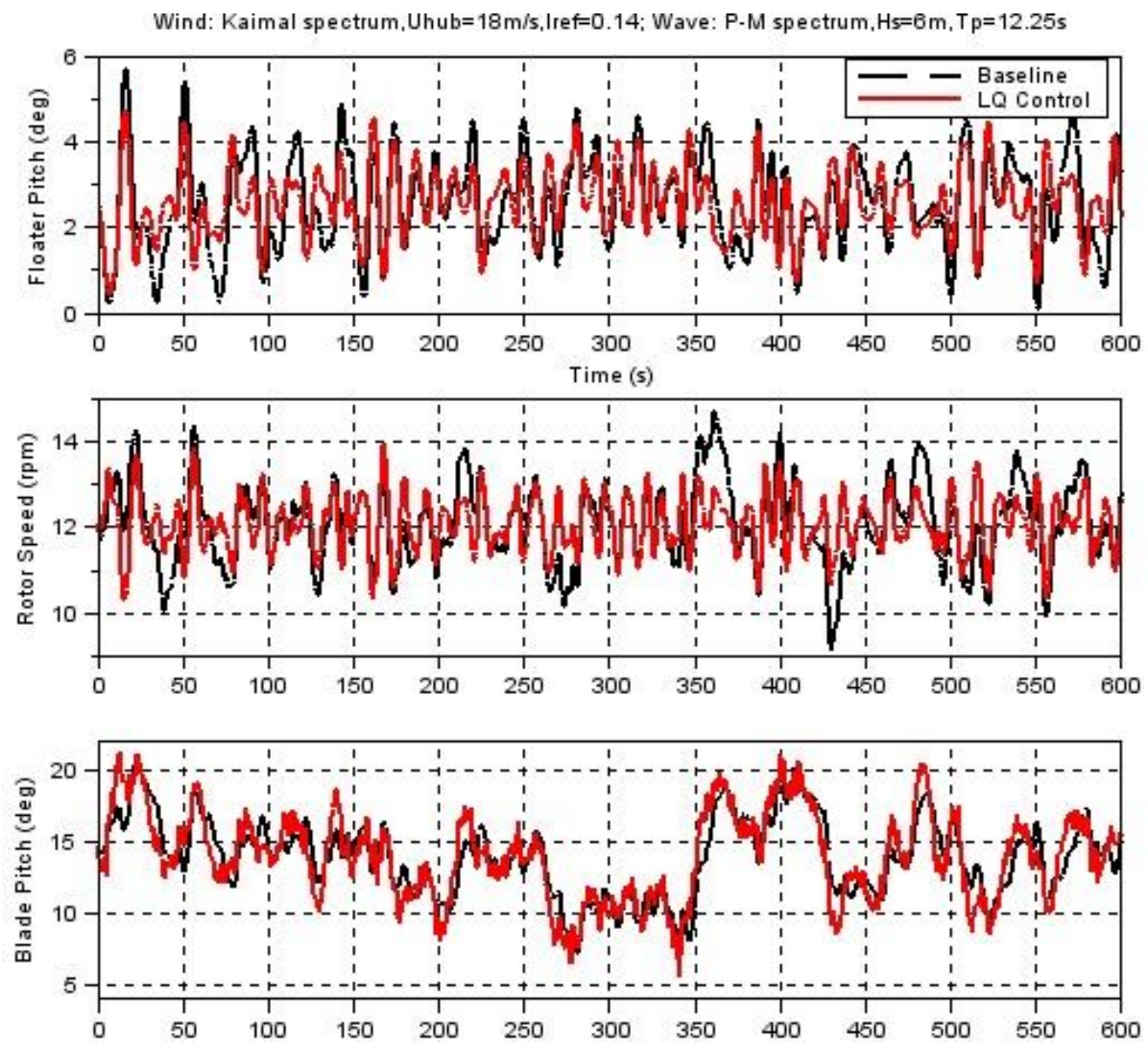

Figure 6. LQ control of a spar FOWT—very rough sea state. 


\section{Discussion and Conclusions}

Figures 4-6 show that a single LQ controller can reduce both rotor speed fluctuations and floater pitch motion in each relevant sea state compared with the PI controller. The collective blade pitch actuator activity increases significantly but remains within the saturation limits. Table 3 shows the standard deviations of rotor speed and floater pitch in the relevant sea states and Table 4 shows the reduction of floater-turbine motions due to LQ control compared with PI control.

Table 3. Proportional-integral (PI) and LQ control performance: standard deviations of rotor speed and floater pitch.

\begin{tabular}{ccccc}
\hline \multirow{2}{*}{ Sea States } & $\begin{array}{c}\text { PI Control } \\
\text { STD of Rotor Speed (rpm) }\end{array}$ & $\begin{array}{c}\text { LQ Control } \\
\text { STD of Rotor Speed (rpm) }\end{array}$ & $\begin{array}{c}\text { PI Control } \\
\text { STD of Floater Pitch (deg) }\end{array}$ & $\begin{array}{c}\text { LQ Control } \\
\text { STD of Floater Pitch (deg) }\end{array}$ \\
\hline Moderate & 0.8582 & 0.2441 & 0.7326 & 0.4099 \\
Rough & 0.8777 & 0.4011 & 0.8004 & 0.5146 \\
Very rough & 0.9360 & 0.6325 & 0.9943 & 0.7758 \\
\hline
\end{tabular}

Table 4. Reduction of floater-turbine motions due to LQ control compared with PI control.

\begin{tabular}{ccc}
\hline Sea States & Rotor Speed Fluctuation Reduction (\%) & Floater Pitch Motion Reduction (\%) \\
\hline Moderate & 71.55675 & 44.04859 \\
Rough & 54.30101 & 35.70715 \\
Very rough & 32.42521 & 21.97526 \\
\hline
\end{tabular}

Table 3 shows that the standard deviations of rotor speed and floater pitch for the baseline PI controller in rough seas are approximately $0.88 \mathrm{rpm}$ and $0.8 \mathrm{deg}$, respectively. These values are reduced to approximately $0.4 \mathrm{rpm}$ and $0.51 \mathrm{deg}$, respectively, due to the designed LQ controller. Table 4 reveals that the reduction of floater-turbine motions depends on the sea state. It is mainly due to the effective attenuation of the low-frequency wind turbulence disturbance, which is associated with the FOWT pitch resonance frequency. The motion reduction in moderate sea state is larger than that in rough and very rough sea states. The simulation results show that a single LQ controller can yield both rotor speed fluctuation reduction of approximately $32-72 \%$ and floater pitch motion reduction of $22-44 \%$ in moderate to very rough sea states compared with a baseline PI controller.

Funding: This research received no external funding.

Conflicts of Interest: The author declares no conflict of interest.

\section{References}

1. Jonkman, J.M. Dynamics Modeling and Loads Analysis of an Offshore Floating Wind Turbine; Tech. Rep. NREL/TP-500-41958; National Renewable Energy Laboratory: Golden, CO, USA, 2007.

2. Pimenta, F.; Kempton, W.; Garvine, R. Combining meteorological stations and satellite data to evaluate the offshore wind power resource of Southeastern Brazil. Renew. Energy 2008, 33, 2375-2387. [CrossRef]

3. Jonkman, J.M.; Butterfield, S.; Musial, W.; Scott, G. Definition of a 5-MW Reference Wind Turbine for Offshore System Development; Tech. Rep. NREL/TP-500-38060; National Renewable Energy Laboratory: Golden, CO, USA, 2009.

4. Jonkman, J.M. Definition of the Floating System for Phase IV of OC3; Tech. Rep. NREL/TP-500-47535; National Renewable Energy Laboratory: Golden, CO, USA, 2010.

5. Goupee, A.J.; Kimball, R.W.; Dagher, H.J. Experimental observations of active blade pitch and generator control influence on floating wind turbine response. Renew. Energy 2017, 104, 9-19. [CrossRef]

6. Bianchi, F.D.; Battista, H.D.; Mantz, R.J. Wind Turbine Control Systems: Principles, Modeling and Gain Scheduling Design, 1st ed.; Advances in Industrial Control; Springer: London, UK, 2007; ISBN 978-1846284922.

7. Fossen, T.I. Handbook of Marine Craft Hydrodynamics and Motion Control, 1st ed.; John Wiley \& Sons Ltd.: Hoboken, NY, USA, 2011; ISBN 978-1119991496. 
8. Perez, T. Ship Motion Control, Advances in Industrial Control Series; Springer-Verlag London Limited: London, UK, 2005; ISBN 978-1-85233-959-3.

9. Fisher, B. Reducing Rotor Speed Variations of Floating Wind Turbines by Compensation of Non-Minimum Phase Zeros. In Proceedings of the European Wind Energy Association Annual Event (EWEA2012), Copenhagen, Denmark, 16-19 April 2012.

10. Fischer, B.; Loepelmann, P. Balancing rotor speed regulation and drive train loads of floating wind turbines. The Science of Making Torque from Wind (TORQUE 2016). J. Phys. Conf. Ser. 2016, 753. [CrossRef]

11. Pedersen, M.D. Stabilization of Floating Wind Turbines. Ph.D. Thesis, Norwegian University of Science and Technology (NTNU), Trondheim, Norway, 2017. in Engineering Cybernetics.

12. Larsen, T.J.; Hanson, T.D. A method to avoid negative damped low frequent tower vibrations for a floating, pitch controlled wind turbine. The Science of Making Torque from Wind. J. Phys. Conf. Ser. 2007, 75, 012073. [CrossRef]

13. Jonkman, J.M. Influence of Control on the Pitch Damping of a Floating Wind Turbine. In Proceedings of the ASME Wind Energy Symposium, Reno, NV, USA, 7-10 January 2008.

14. Dinh, V.N.; Basu, B. Passive control of floating offshore wind turbine nacelle and spar vibrations by multiple tuned mass dampers. Struct. Control Health Monit. 2015, 22, 152-176. [CrossRef]

15. Det Norske Veritas (DNV-GL). Standard DNVGL-ST-0119. In Floating Wind Turbine Structures; Det Norske Veritas (DNV-GL): Oslo, Norway, July 2018.

16. Jonkman, J.M.; Buhl, M.L. FAST User's Guide; Tech. Rep. NREL/EL-500-38230; National Renewable Energy Laboratory: Golden, CO, USA, 2005.

17. Bossanyi, E.A. GH Bladed Theory Manual; Document No. 282/BR/009, Issue No. 12; Garrad Hassan and Partners Limited: Bristol, UK, 2003.

18. Larsen, T.J.; Hansen, A.M. How 2 HAWC2, the User's Manual; DTU Rep. Risø-R-1597; Technical University of Denmark (DTU): Roskilde, Denmark, 2007.

19. Chakrabarti, S.K. Handbook of Offshore Engineering, 1st ed.; Elsevier: Amsterdam, The Netherlands, 2005; ISBN 978-0080443812.

20. Faltinsen, O.M. Sea Loads on Ships and Offshore Structures; Cambridge University Press: Cambridge, UK, 1990; ISBN 0-521-45870-6.

21. Journée, J.M.J.; Massie, W.W. Offshore Hydromechanics; Delft University of Technology: Delft, The Netherlands, 2001.

22. Karimirad, M. Modeling aspects of a floating wind turbine for coupled wave-wind-induced dynamic analyses. Renew. Energy 2013, 53, 299-305. [CrossRef]

23. Housseine, C.O.; Monroy, C.; Hauteclocque, G. Stochastic Linearization of the Morison Equation Applied to an Offshore Wind Turbine. In Proceedings of the 34th ASME International Conference Ocean, Offshore and Arctic Engineering (OMAE2015), St. John's, NL, Canada, 31 May-5 June 2015.

24. Homer, J.R.; Nagamune, R. Physics-based 3-D control-oriented modeling of floating wind turbines. IEEE Trans. Control Syst. Technol. 2018, 26, 14-26. [CrossRef]

25. Betti, G.; Farina, M.; Guagliardi, G.A.; Marzorati, A.; Scattolini, R. Development of a control-oriented model of floating wind turbines. IEEE Trans. Control Syst. Technol. 2014, 22, 69-82. [CrossRef]

26. Betti, G.; Farina, M.; Marzorati, A.; Scattolini, R.; Guagliardi, G.A. Modeling and Control of a Floating Wind Turbine with Spar Buoy Platform. In Proceedings of the 2nd IEEE International Energy Conference \& Exhibition, Florence, Italy, 9-12 September 2012.

27. Sandner, F.; Schlipf, D.; Matha, D.; Seifried, R.; Cheng, P.W. Reduced Nonlinear Model of a Spar-Mounted Floating Wind Turbine. In Proceedings of the 11th German Wind Energy Conference, Bremen, Germany, 7-8 November 2012.

28. Fontanella, A.; Bayati, I.; Belloli, M. Linear coupled model for floating wind turbine control. Wind Eng. 2018, 42, 115-127. [CrossRef]

29. Anderson, B.D.O.; Moore, J.B. Optimal Control: Linear Quadratic Methods, 1st ed.; Dover Publications: New York, NY, USA, 2007; ISBN 978-0-486-45766-6.

30. Lindeberg, E. Optimal Control of Floating Offshore Wind Turbines. Master Thesis, Engineering Cybernetics, Norwegian University of Science and Technology (NTNU), Trondheim, Norway, 2009. 
31. Ramos, R. Optimal Vibration Control of Floating Wind Turbines in the Presence of Nonlinearities. In Proceedings of the 32nd ASME International Conference Ocean, Offshore and Arctic Engineering (OMAE2013), Nantes, France, 9-14 June 2013.

32. Lemmer, F.; Schlipf, D.; Cheng, P.W. Control design methods for floating wind turbines for optimal disturbance rejection. The Science of Making Torque from Wind (TORQUE 2016). J. Phys. Conf. Ser. 2016, 753. [CrossRef]

33. Christiansen, S.; Knudsen, T.; Bak, T. Optimal Control of a Ballast-Stabilized Floating Wind Turbine. In Proceedings of the IEEE International Symp. Computer-Aided Control Systems Design (CACSD), Denver, CO, USA, 28-30 September 2011.

34. Namik, H.; Stol, K. Individual blade pitch control of a spar-buoy floating wind turbine. IEEE Trans. Control Syst. Technol. 2014, 22, 214-223. [CrossRef]

35. Driscoll, F.; Jonkman, J.; Robertson, A.; Sirnivas, S.; Skaare, B.; Nielsen, F.G. Validation of a FAST model of the Statoil-Hywind demo floating wind turbine. Energy Procedia 2016, 94, 3-19. [CrossRef]

36. Karimirad, M.; Moan, T. A simplified method for coupled analysis of floating offshore wind turbines. Mar. Struct. 2012, 27, 45-63. [CrossRef]

37. International Electrotechnical Commission (IEC). Technical Committee TC88: Wind Turbines. In Wind Turbines-Part 1: Design Requirements; IEC 61400-1; International Electrotechnical Commission (IEC): Geneva, Switzerland, 2005.

(C) 2018 by the author. Licensee MDPI, Basel, Switzerland. This article is an open access article distributed under the terms and conditions of the Creative Commons Attribution (CC BY) license (http://creativecommons.org/licenses/by/4.0/). 